\title{
Temperature modes of the contactor contacts during the test for the limiting breaking capacity
}

\author{
E.G. Egorov ${ }^{1}$, A.G Kulagina ${ }^{1}$, N.Yu. Luiya ${ }^{1,2, *}$, R.V. Fedorov ${ }^{1,3}$, and V.N. Pichugin ${ }^{4}$ \\ ${ }^{1}$ Chuvash State University named after I.N. Ulyanov, 428015, Chuvash Republic, Cheboksary, Moskovsky pr. 15 \\ ${ }^{2}$ Cheboksary Electrical Device Plant, Russia, 428020, Chuvash Republic, Cheboksary, I. Yakovlev Ave. 5 \\ ${ }^{3}$ Electropribor Plant AO, Alatyr, Russia, 429820, Chuvash Republic, Alatyr, pl. Octyabrskoy Revolucii pl. 23. \\ ${ }^{4}$ Alatyr Branch of the Chuvash State University named after I.N. Ulyanov, 429820, Russia, Chuvash Republic, Alatyr, Pervomayskaya st. \\ 70
}

\begin{abstract}
The processes of electric arc quenching of an electromagnetic contactor during testing for ultimate breaking capacity are considered. The conditions for facilitating the successful arc quenching when turning off the limiting currents are shown: by reducing the phase shift between current and voltage, by reducing the amplitude of the restriking and recovery voltages. The processes of anode heating during arcing (heat saturation mode), after the change of polarity and transition of the current through zero, processes on the cathode in the temperature equalization mode are considered. The mathematical models of cathode thermal processes adressed the heat fluxes of the ionic component and evaporation. The mathematical models of anode thermal processes in the temperature equalization mode took into account the heat fluxes of the ionic component, thermionic emission, and evaporation. The calculations were carried out for the averaged values of thermophysical coefficients for copper, since the arc base moves from the contacts to the contact holders, which are made of copper or its alloys. The calculation results showed that the used mathematical models of thermal processes are appropriate both for the cathode and for the anode. This was confirmed by the results of previously performed and published experimental and theoretical studies of thermal processes at the switching contacts of electrical devices.
\end{abstract}

\section{Introduction}

The microprocessor devices are now being actively introduced in the power industry. However, electromechanical devices are still the key elements in products for which reliable operation is especially important. The reliability of electromechanical devices, in particular electromagnetic contactors, is confirmed by testing for the ultimate switching capacity.

The main switching elements of an electromagnetic contactor are electrical contacts that pass currents that are many times higher than the rated ones. As a result, the electrical contacts are exposed to significant thermal loads, which can cause the contactor failure and lead to an accident in the electrical equipment it controls.

It is proposed to evaluate the device reliability using the reliability index basing on the analysis of the main failure types of $\mathrm{AC}$ contactor under various load conditions [16]. The reliability index is the degree of failure rate, which is determined by six levels in accordance with the maximum failure rate.

The reliability of the residual life prediction and the contactor reliability evaluation depend on the technical condition of the contacts. In [11], an online reliability evaluation method is proposed, that associates contact erosion loss, the performance degradation process, and residual electrical life prediction.

The technical condition of contacts depends on many factors, in particular, on the degree of contact heating, the temperature field of the contact gap, contact material, etc. The temperature field of the AC contactor is determined by mathematical modeling in ANSYS taking into account heating and heat dissipation [13]. The calculation takes into account the heating of the electromagnetic system, as well as the resistance of the circuit and contact.

In $[12,14,15]$, a new contact material made of silver and tin oxide is considered for various categories of AC3, AC-4 application. The theoretical and experimental studies, as well as the basic physical and applied properties of the developed contact material, are presented. The authors also propose a method for producing tin oxide doped with the rare earth element $\mathrm{Ce}$ and consider a mechanism of contact material failure.

It is important to increase the reliability of system contacts, therefore studies of the temperature conditions of contacts of electrical devices are relevant.

*Corresponding author: nataliluiya@ mail.ru 


\section{Materials and methods}

The successful disconnection of the limiting switching currents by the electromagnetic contactor is ensured by: limiting the amplitude of the active resistance current of the arising arc; reducing the angle between current and voltage; decreasing the amplitude of the restriking and recovery voltages [1]. Figure 1 shows transient processes occurring when $\mathrm{AC}$ is disconnected by an electromagnetic contactor, and the influence of the arc resistance.

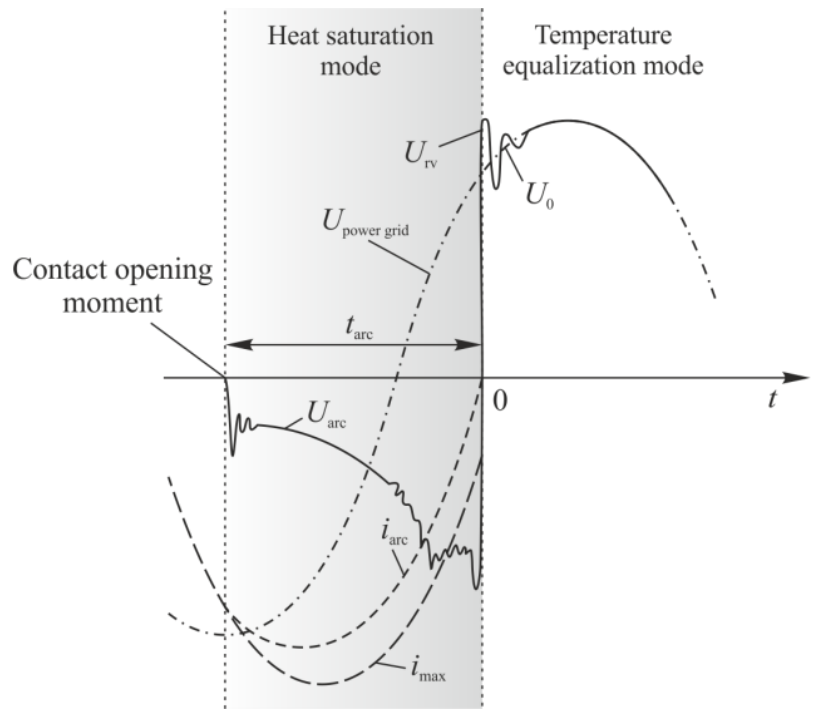

Fig. 1. Breaking of the limiting (maximum) current: $i_{\text {arc, }} u_{\text {arc }}$ are the current and voltage of electric arc, $U_{\mathrm{rv}}$ is the restriking voltage characteristic, $i_{\max }$ is the maximum breaking current.

It is known that the restoration of dielectric strength after the arc current passed through zero is governed by near-cathode processes [1]. Namely, the processes of restoring the dielectrical strength are governed by thermophysical and elementary electrophysical processes at the anode and in the arc column in the heat saturation mode, and after the current polarity reversal - in the adjacent residual arc column in the temperature equalization mode $[2,3,4,5]$.

Thermal processes at contacts are considered basing on the well-known differential equation of heat conduction $[2,3]$.

$$
\frac{\partial T}{\partial t}=\operatorname{adiv} \nabla T
$$

where $a$ is the thermal diffusivity; $\nabla$ is the Hamiltonian.

The works [2,3] present mathematical models of thermal processes during electrical discharges for cathode and anode. It is shown that it is necessary to take into account specific boundary conditions:

a) For anode

$$
F_{\mathrm{a}}=F_{\mathrm{e}}^{\prime}-F_{\text {eva }},
$$

b) For cathode

$$
F_{\mathrm{c}}=F_{i}-F_{\text {te }}-F_{\text {eva }}
$$

where $F_{\mathrm{e}}^{\prime}, F_{i}$ are the heat flux densities due to the bombardment of cathodes with electrons and ions;

$F_{\text {eva }}, F_{\text {te }}$ are the heat flux densities of evaporation in thermionic emission.

The workability and legitimacy of the developed mathematical models of thermal processes on the switching contacts of electrical devices are considered in $[2,3]$. The reliability of the obtained results was evaluated according to the results of studies $[4,6]$ for some switching modes.

The anode thermal processes in heat saturation mode (see Figure 1) were studied. The obtained results showed that it is advisable to perform calculations basing on the mathematical model, shown below, (4)-(7). For the case of one-dimensional heat propagation from a flat source with a moving evaporation front deep into the electrode it has the following form [2]:

$$
\begin{gathered}
\frac{\partial T(x, t)}{\partial t}=a \frac{\partial^{2} T(x, t)}{\partial x^{2}}+V_{0} \exp \left[-\frac{T_{\mathrm{m}}}{T(0, t)}\right] \frac{\partial T(x, t)}{\partial x}, \\
-\frac{\partial T(0, t)}{\partial x}=\frac{1}{a C_{V}}\left(F_{i}-F_{\mathrm{te}}-F_{\mathrm{eva}}\right) \\
\frac{\partial T(\infty, t)}{\partial x}=0 ; \quad \frac{\partial T(x, \infty)}{\partial x}=0
\end{gathered}
$$$$
T(x, 0)=T_{0} e^{-\frac{x^{2}}{4 \alpha t_{0}}},
$$

where $V_{0}$ is the speed of sound in metal, $t_{\text {arc }}$ is the duration of the heat source operation until the moment of zero current (see Figure 1).

The cathode boundary condition (5) includes the heat fluxes of the ionic component $F_{i}$, thermionic emission $F_{\text {te }}$ and evaporation $F_{\text {eva }}$, which significantly depend on the applied probe pulses [2, 3, 4].

$$
F_{i}=\frac{\psi}{1+\psi} \mu(1+\eta+v) U_{\mathrm{c}} j_{\mathrm{c}}
$$

where $\psi=\frac{j_{i}}{j_{\mathrm{e}}}, j_{\mathrm{c}}=j_{i}+j_{\mathrm{e}}, j_{i}, j_{\mathrm{e}}$ are the densities of ion and electron current,

$\mu(1+\eta+v)$ is the total coefficient taking into account the transfer of energy to the cathode by an individual ion.

For the rest time of the strength recovery (temperature equalization mode) $F_{i}=0$.

Evaporation rate depends only on the temperature of the evaporation front and the contact material $[2,4]$ :

$$
F_{\text {eva }}=F_{0} \exp \left(-\frac{T_{\mathrm{m}}}{\mathrm{T}}\right)
$$




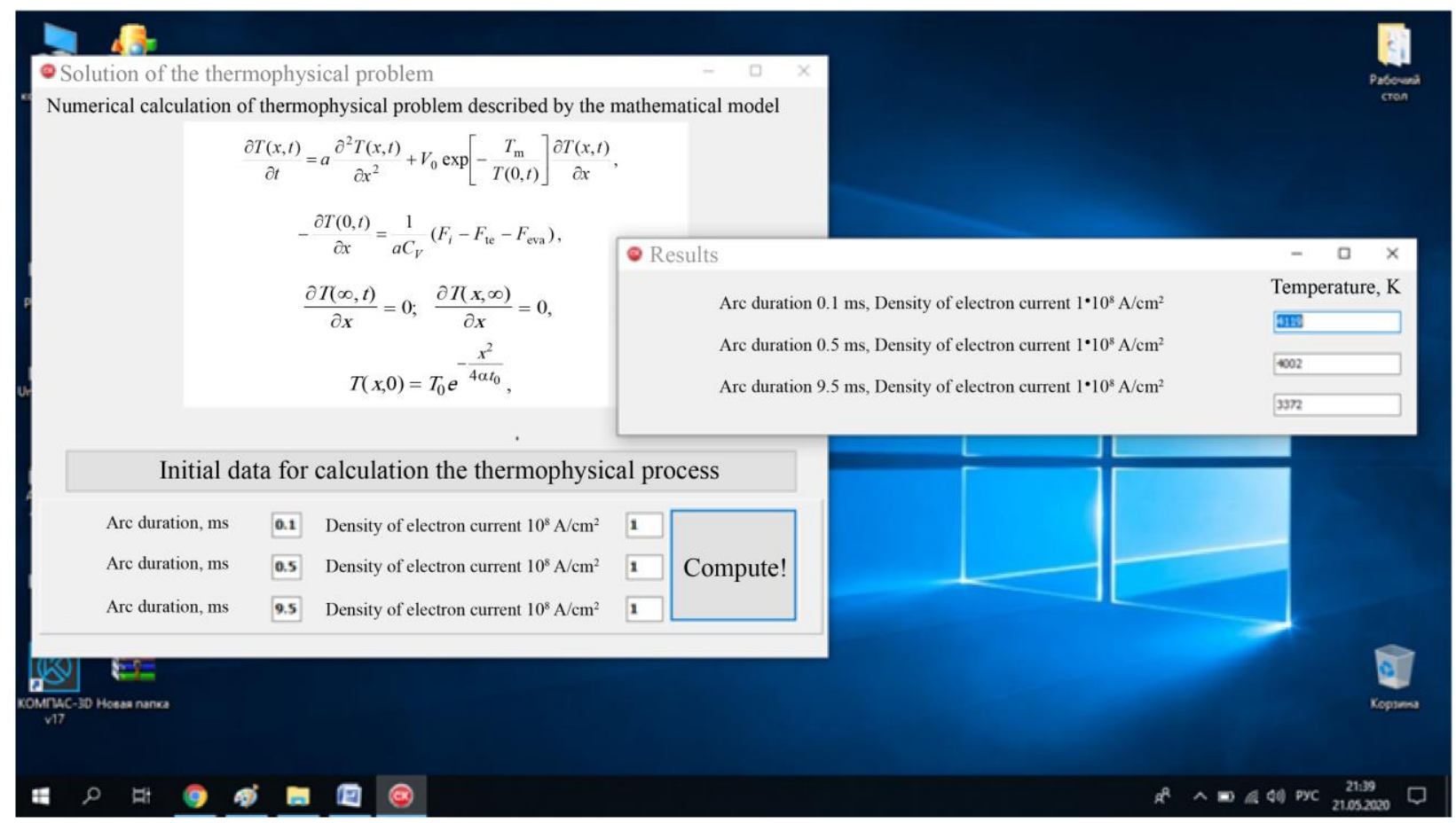

Fig. 2. The software tool for solving a thermophysical problem by the finite element method.

where $F_{0}$ and $T_{\mathrm{m}}$ are the typical characteristics of the evaporation process (constant for each metal).

Thermoelectronic emission of electrons from the cathode surface is also associated with its cooling. Specific power is determined by the expression [2]:

$$
F_{\mathrm{e}}=\left(\frac{j_{\mathrm{e}}}{\mathrm{e}}\right) q_{\mathrm{e}}
$$

where $\frac{j_{\mathrm{e}}}{\mathrm{e}}$ is the amount of emitted electrons from a unit area per unit of time;

$q_{\mathrm{e}}$ is the energy lost by the cathode during emission of one electron.

The system of equations (4)-(7) together with equations (8-10) make it possible to calculate the anode thermal state (in the heat saturation mode), which, after changing the current direction (see Figure 1), becomes the cathode (temperature equalization mode). This thermal state is taken as an initial condition in the mathematical model (4)-(7).

The solution of this thermophysical problem was carried out by a numerical finite element method. The possibility of using this method was shown when solving problems of this kind [9].

\section{Results and discussion}

The necessary data for calculating the thermophysical process is presented in Table 1. It also shows the criterion and thermophysical constants for copper [7], since the arc bases during the time of its burning have time to move from the contact solders to horns made of copper or its alloys.

During the calculations, the values of $C_{V}, \lambda$ are averaged for $\mathrm{T}=0.5 T_{\text {melt }}$, where $T_{\text {melt }}$ is the melting point. This assumption should not lead to large errors [2, 3].

To automate the problem solution, a software tool has been developed in the integrated development environment C ++ Builder XE10.2 [9, 10]. The program interface is shown in Figure 2.

Figure 3 presents the results of investigation the temperature modes of the contacts of the electromagnetic contactor. They are presented as relationships between the contact temperature and the arc burning time for

Table 1.

\begin{tabular}{|c|c|c|c|c|c|c|}
\hline$\lambda, \mathbf{W} / \mathbf{m} \cdot \mathbf{K}$ & $C_{V, \mathrm{~J} / \mathrm{K} \cdot \mathbf{m}^{3}}$ & $\alpha=\lambda / C_{V}, \mathbf{m}^{2} / \mathrm{s}$ & $V_{0}, \mathbf{m} / \mathbf{s}$ & $T_{m,}, \mathbf{K}$ & $G_{0,1 / \mathrm{m}^{2} \cdot \mathrm{s}}$ & $q_{\mathrm{p}}, \mathrm{eV}$ \\
\hline $3.15 \cdot 10^{2}$ & $3.40 \cdot 10^{6}$ & $9.3 \cdot 10^{-5}$ & 3666 & 40200 & $3.08 \cdot 10^{32}$ & 3.45 \\
\hline $\begin{array}{l}F_{0}=G_{0} \cdot q_{\mathrm{p}} \\
\mathrm{W} / \mathrm{m}^{2}\end{array}$ & $L_{V}, \mathrm{~J} / \mathrm{m}^{3}$ & $r_{V}, \mathrm{~J} / \mathrm{m}^{3}$ & $T_{\text {melt }}{ }^{\circ} \mathrm{K}$ & $T_{\text {boil }},{ }^{\circ} \mathrm{K}$ & $\mathrm{K}, \mathrm{eV} / \mathrm{K}$ & $W_{\text {out }}, \mathrm{eV}$ \\
\hline $1.7 \cdot 10^{4}$ & $1.32 \cdot 10^{9}$ & $4.9 \cdot 10^{10}$ & 1356 & 2873 & 0.8625 & 4.4 \\
\hline$\mu$ & $\eta$ & v & $U_{\mathrm{c}}, \mathrm{V}$ & $U_{i}, \mathrm{~V}$ & $e, \mathrm{C}$ & \\
\hline$\sim 1$ & 0.1 & 0.234 & 16 & 7.72 & $1.6 \cdot 10^{-19}$ & \\
\hline
\end{tabular}


various current densities. The limiting breaking current is $1000 \mathrm{~A}$, the limiting voltage is $726 \mathrm{~V}$. For the current density $j_{\mathrm{e}}=10 \cdot 10^{8} \mathrm{~A} / \mathrm{cm}^{2}$, the system of equations (4)(7) has no solutions.

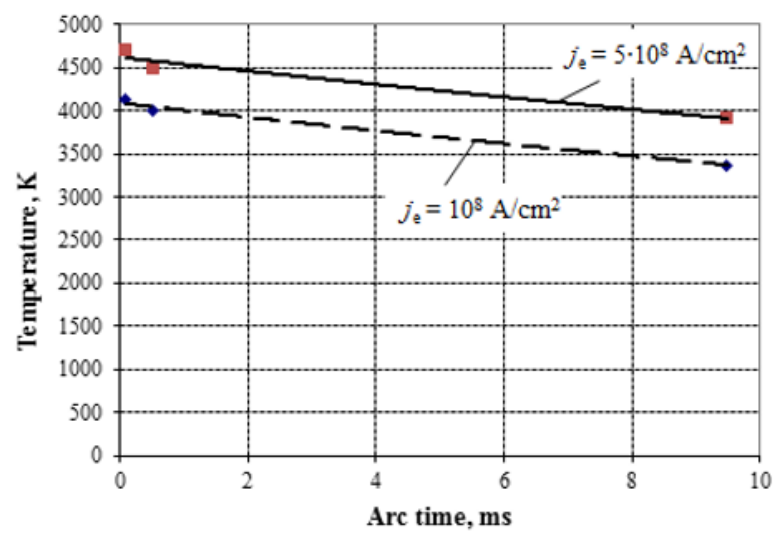

Fig. 3. Temperature versus arc time plot for various current densities.

The calculated contact surface temperatures of 4000 $4600 \mathrm{~K}$ should cause significant phase transformations of the contact material (melting and boiling) in the zones adjacent to electric arc. The previously performed switching tests of contactors for ultimate breaking capacity showed that the mathematical model (4)-(7) can be used for preliminary calculation of the contact surface temperature [1-6].

It should be noted that it is advisable to clarify the appropriateness of this mathematical model for assessing the performance of contactors. At the same time, the switching capacity of contactors must be confirmed by testing.

\section{Conclusions}

1) The considered technique for studying the temperature conditions of contacts of electromagnetic contactors can be useful at the preliminary stages of development, as well as the process of their modernization.

2) In accordance with the normative and technical documentation, the operability of electromagnetic contactors must be confirmed by direct switching tests for the ultimate switching capacity. However, the disconnection of large powers can have a serious negative impact on the parameters and performance of the supply network.

\section{References}

1. I.S. Taev, Electrical contacts and arc-extinguishing apparatus of low voltage devices, 424 (Moscow: Energiya, 1973).

2. A.G. Goloveyko, Thermophysical processes at the anode under conditions of a powerful pulsed discharge, Inzhenerno-Fizicheskiy Zhurnal, 15(6). 51-58 (1968).
3. A.G. Goloveyko, Elementary and thermophysical processes at the cathode under a powerful pulsed discharge, Inzhenerno-Fizicheskiy Zhurnal, 14(3), 25-31 (1968).

4. E.G. Egorov, Testing and study of low-voltage switching electrical devices, 448 (Cheboksary: Chuvash University Publishing House, 2000)

5. G.A. Mesyac, Ectons. Part 1., 184 (Ekaterinburg: Nauka, 1993)

6. I.S. Taev, E.G. Egorov, Yu.E. Gorshkov, Influence of the energy of probing pulses on the measured values of restoring strength, Electrotekhnika, 6, 5658 (1981).

7. A.S. Okhotin, Thermal conductivity of solids, 320 (Moscow: Energoatomizdat, 1984)

8. V.V. Kaplan, V.M. Nashatyr, Synthetic testing of high voltage circuit breakers, 200 (Moscow: Energiya, 1980)

9. P. Silvester. R. Ferrari, Finite Elements for Electrical Engineers (Cambridge University Press, 1983).

10. N.B. Kultin, Self-teaching guide on $C++$ Builder, 300 (Saint-Petersburg: BHV-Peterburg, 2004)

11. L. Li, Electrical performance degradation model and residual electrical life prediction for AC contactor, IEEE Transactions on components and packaging technologies, 10(3), 400-417 (2020) doi: 10.1109/TCPMT.2020.2966516.

12. S. Shang, The performance degradation comparison test and failure mechanism of silver metal oxide contact materials, 2019 IEEE Holm Conference on Electrical Contacts - Milwaukee, WI, USA, 335343 (2019), doi: 10.1109/HOLM.2019.8923916.

13. G. Liu, Thermal simulation of small capacity AC contactor based on ANSYS, 26th International Conference on Electrical Contacts (ICEC 2012) Beijing, China, 479-483 (2012), doi: 10.1049/cp.2012.0701.K.

14. H. Cinaroglu, Application of a new $\mathrm{Ag} / \mathrm{SnO} 2$ contact material in AC-contactors, 2017 IEEE Holm Conference on Electrical Contacts - Denver, CO, USA, 215-220 (2017), doi: 10.1109/HOLM.2017.8088089.

15. J. Wang, Simulation and experimental research on electrical properties of $\mathrm{AgSnO} 2$ contact materials doped with rare earth element Ce, 2018 IEEE Holm Conference on Electrical Contacts - Albuquerque, NM, USA, 119-123 (2018), doi: 10.1109/HOLM.2018.8611637.

16. W. Lili, Reliability test and reliability evaluation methods of AC contactor, 27th International Conference on Electrical Contacts (ICEC) Germany, 518-522 (2014). 